\title{
Impact of positive practices on turnover intention, in-role performance and organisational citizenship behaviour
}

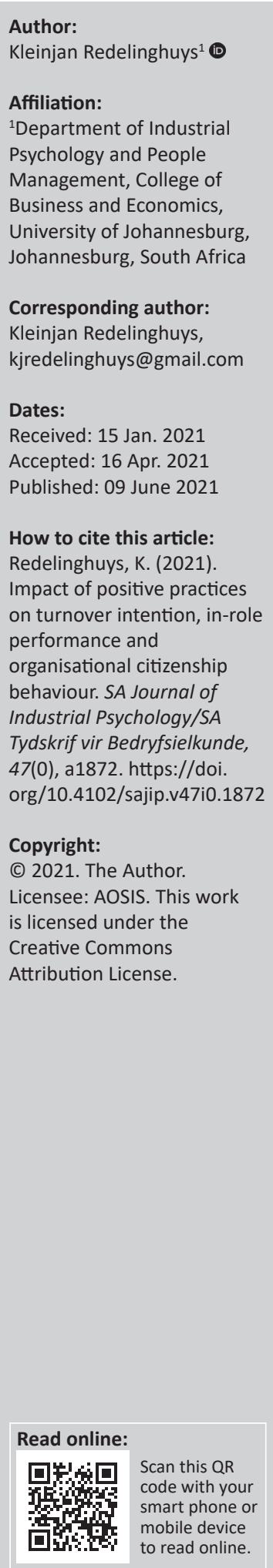

Orientation: The literature on positive organisational scholarship (POS) could offer valuable suggestions on how to rekindle a sense of positivity amongst teachers. Under the POS umbrella, the current study specifically focusses on positive practices, as the research study shows the importance of a positive school climate for teachers and learners.

Research purpose: This study set out to inspect associations amongst positive practices, turnover intention, in-role performance and organisational citizenship behaviours (OCBs) (towards others and the organisation).

Motivation for the study: Although positive practices is not a novel construct, scientific enquiry into the topic has been scarce.

Research approach/design and method: A cross-sectional survey design with 258 secondary school teachers from the Sedibeng East and West districts was used. The Positive Practices, Turnover Intention, OCB and In-Role Behaviour scales were administered. Structural equation modelling was used for hypotheses testing.

Main findings: The results of this study confirmed the negative association between positive practices and turnover intention, whereas positive associations were established amongst positive practices, in-role performance (to a lesser extent) and the two different types of OCBs used in this study.

Practical/managerial implications: Organisations are faced with two options: create a respectful, supportive, caring, inspirational, meaningful and forgiving organisational environment for employees and see them prosper and take the organisation to greater heights, or treat them poorly and bear the consequences.

Contribution/value-add: This study makes a valuable contribution to POS through the assessment of outcomes associated with positive practices that have not been studied previously.

Keywords: positive practices; turnover intention; in-role performance; organisational citizenship behaviour; teachers.

\section{Introduction}

This study set out to inspect associations amongst positive practices, turnover intention, in-role performance and organisational citizenship behaviours (OCBs) (towards others and the organisation). 'Teaching has been ranked as one of the most stressful professions in various cultural and educational contexts' (Saloviita \& Pakarinen, 2021, para. 3). Consequently, an extensive literature base has been built around the negative outcomes associated with teaching, investigating prominent issues such as victimisation (e.g. Yang et al., 2019), depression (e.g. Martínez-Monteagudo, Inglés, Granados, Aparisi, \& García-Fernández, 2019), burnout (García-Carmona, Marín, \& Aguayo, 2019), musculoskeletal disorders (e.g. Ng, Voo, \& Maakip, 2019), and time pressure and discipline problems (Skaalvik \& Skaalvik, 2018) amongst others. Although it is important to focus on negative issues teachers face and the events that precede it, it is also essential to cast attention to antecedents that may promote positive outcomes amongst teachers. The literature on positive organisational scholarship (POS; see Cameron \& Spreitzer, 2011) could offer valuable suggestions on how to rekindle a sense of positivity amongst teachers. Under the POS umbrella, this study specifically focusses on positive practices, as this research shows the importance of a positive school climate for teachers and learners alike (Collie, Shapka, \& Perry, 2012). 


\section{Positive practices}

In an attempt to capture behaviours and characteristics of positivity in organisations, Cameron, Mora, Leutscher and Calarco (2011) derived a list of six positive practices: (1) respect, integrity and gratitude; (2) compassionate support; (3) caring; (4) meaning; (5) inspiration; and (6) forgiveness. Respect, integrity and gratitude ${ }^{1}$ refer to practices where employees trust each other, treat one another respectfully, display integrity, show belief in others, and openly express their gratefulness towards colleagues. Compassionate support ${ }^{2}$ involves assisting and caring for coworkers who are facing adversity, providing emotional support and compassion, building strong social ties, being kind-hearted and cherishing each other's unique talents. Caring involves showing genuine interest and concern to fellow workers, nurturing friendships and being responsive to one another. Meaning involves finding elevation, rejuvenation, meaning, motivation and purpose at work. Inspiration involves finding inspiration in one another, sharing enthusiasm with each other and publicly praising the good in others. Finally, forgiveness involves reserving judgement when any blunders are made, correcting errors without pointing fingers and not keeping record of any mistakes made by colleagues.

Although positive practices is not a novel construct, scientific enquiry into the topic has been scarce (Janse van Rensburg \& Rothmann, 2020). Organisations with positive practices in their arsenal are more inclined to retain their personnel and attain greater levels of organisational efficiency (Cameron et al., 2011). At the team level, positive practices have been associated with task performance and work engagement (Geue, 2018). Within the South African context, Rautenbach (2015) established a positive association between three positive practices (coined positive emotions, support and inspiration) and employee flourishing in the fast-moving consumer goods industry. Amongst secondary school teachers in the North West province, Fouché (2015) observed that two positive practices (meaning and inspiration) related to the psychological well-being of employees. Similarly, Redelinghuys, Rothmann and Botha (2019) found that positive practices related to the emotional, psychological and social well-being of secondary school educators in two Gauteng districts. More recently, Janse van Rensburg and Rothmann (2020) uncovered that the perceived absence of positive organisational practices related to diminished employee well-being, overload perceptions, unsatisfactory workplace relationships and a lack of personenvironment fit and role clarity.

Even though in-role performance in relation to positive practices has been studied previously, the current study differs from that of Cameron et al.'s (2011) study by focussing on positive practices and in-role performance at the individual level of analysis. Additionally, this study includes individual-level outcomes (turnover intention and OCBs) that have not been assessed in relation to positive practices to the best of the author's knowledge.

1.Hereafter referred to as respect.

2.Hereafter referred to as support.

\section{In-role performance, turnover intention and organisational citizenship behaviours as outcomes of positive practices}

Teacher retention and performance are important focus points within the South African education system (Redelinghuys et al., 2019). Therefore, it is vital to grasp the factors that inhibit teacher attrition (Ryan et al., 2017), especially because of the longstanding problem of teachers leaving the profession (Perryman \& Calvert, 2020). Turnover intention signals an employee's premeditated intent to pursue alternative employment opportunities (Tett \& Meyer, 1993). Schools should by all means necessary retain competent staff members, as successful educational institutions depend on teachers' excellence (i.e. teachers performing well and exceeding expectations) (Imran, Allil, \& Mahmoud, 2017). Inrole performance, also known as task performance, indicates the formal work activities employees are expected to execute as specified in their work contracts (Borman \& Motowidlo, 1997; Williams \& Anderson, 1991). Fouché (2015) contends that South African teachers often do not possess the necessary qualifications and in many cases their performance is unsatisfactory. Consequently, low teacher performance detrimentally impacts the quality of education students receive (Fouché 2015). Thus, it is key for schools to pinpoint and institutionalise factors that may contribute towards better performance of teachers. Individual performance is however not bound to merely formal job tasks but also behaviours that transcend it. Organisational citizenship behaviours reflect beneficial employee actions that exceed job expectations (Lambert, 2006). Williams and Anderson (1991) suggested that a distinction could be made between two types of OCBs: (1) OCB-I and (2) OCB-O. The first refers to aid towards colleagues, ${ }^{3}$ whilst the latter reflects helping behaviours directed at one's organisation ${ }^{4}$. High-performing schools rely on the eagerness of teachers to go above and beyond of what is expected from them (DiPaola \& TschannenMoran, 2001). This necessitates establishing antecedents that may encourage OCB.

A possible avenue through which positive practices may relate to the outcomes of the study is social exchange theory (SET). Cropanzano and Mitchell (2005) suggest that SET is best described as an amalgamation of various conceptual frameworks rather than a single theory. One of its basic tenets is the reciprocity principle (Cropanzano \& Mitchell, 2005). A positive reciprocity orientation entails the inclination of an employee to respond positively towards his or her organisation and/or colleagues when positive treatment is received (Cropanzano \& Mitchell, 2005). The same principle also applies to negative or unfavourable treatment. Consequently, social exchange relationships blossom when organisations look after their employees, as this promotes positive employee behaviours and attitudes that are beneficial to all the involved parties (Cropanzano \& Mitchell, 2005). For

3.The study uses the term OCB others in the rest of the article to describe this phenomenon.

4.The study uses the term ОСВ organisation in the rest of the article to describe this phenomenon. 
example, studies have found that when exchange relationships are formed, employees do not merely reciprocate through performance but also engage in behaviours that transcend their formal work tasks (Mitchell, Cropanzano, \& Quisenberry, 2012). In the context of the current study, the presence of positive practices (positive treatment by the organisation and/or colleagues) should propel employees to positively respond to their organisation and colleagues through lowered turnover intention, as well as elevated performance and helping behaviours.

Emanating from the preceding discussion, the following hypotheses were formulated:

- Hypothesis 1: Positive practices negatively associate with turnover intention.

- Hypothesis 2: Positive practices positively associate with in-role performance.

- Hypothesis 3: Positive practices positively associate with OCB (others).

- Hypothesis 4: Positive practices positively associate with OCB (organisation).

\section{Research design Research approach}

This study used a quantitative cross-sectional survey research design. This approach enabled the researcher to structurally model the relationships between the variables used in the study and in the process accept or reject the study hypotheses.

\section{Research method}

\section{Participants}

The study included 258 participants gathered through convenience sampling. Schools within relatively close proximity to the researcher were chosen to limit researchrelated expenses. Although a probability sampling technique would have been more ideal, it was not feasible for a nonfunded project. In the recruitment and data collection phases, several stumbling blocks were encountered, which to a certain extent influenced the heterogeneity of the sample. These include (1) principals rejecting the invitation to participate on behalf of their school; (2) principals accepting the invitation to participate on behalf of their school, but no one participated; (3) no response from various principals; and (4) an inability to make contact with schools because of faulty telephone numbers and/or email addresses (this was particularly a problem with rural schools). The participants' mean age equalled 39.97 years (median $=39$, standard deviation $[S D]=12.45)$. Frequencies and percentages (ranging from highest to lowest) for the different biographical categories are reported next; ${ }^{5}$ gender: women $(n=190,73.70 \%)$ and men $(n=62,24 \%)$. Racial groups included were: white people $(n=192,74.40 \%)$, black 5. Where percentages do not add up to a $100 \%$, missing values were involved.
African people $(n=48,18.60 \%)$, Indian and / or Asian $(n=9$, $3.50 \%)$ and mixed race $(n=2,0.8 \%)$; marital status: married $(n=158,61.20 \%)$, single $(n=45,17.40 \%)$, living with partner $(n=18,7 \%)$, divorced $(n=18,7 \%)$ and widowed $(n=4$, $1.60 \%)$; highest educational level: degree $(n=115,44.60 \%)$, postgraduate degree $(n=94,36.40 \%)$, diploma $(n=39$, $15.10 \%)$ and matric $(n=4,1.60 \%)$; experience: more than 10 years $(n=134,51.90 \%)$ and $0-10$ years $(n=104,40.30 \%)$; job position: teacher $(n=204,79.1 \%)$, head of department ( $n=30,11.6 \%)$, vice-principal $(n=10,3.9 \%)$ and principal $(n=6,2.3 \%)$.

\section{Measuring instruments}

The Positive Practices Questionnaire (PPQ; Cameron et al., 2011) measured positive practices. The scale consists of 29 items recorded on a five-point scale, ranging from 1 (strongly disagree) to 5 (strongly agree). The PPQ embodies six dimensions: respect, support, caring, meaning, inspiration and forgiveness. Respect (e.g. ' $[w]$ e show appreciation for one another') and support (e.g. ' $[w]$ e show kindness to one another') were both measured by seven items. Inspiration (e.g. '[w]e communicate the good we see in one another') and forgiveness (e.g. '[w]e do not blame one other when mistakes are made') were both measured by three items. Additionally, caring was measured by four items (e.g. 'We genuinely care about each other') and meaning by five items (e.g. ' $[w]$ e feel that our work has profound meaning'). In a South African study, Redelinghuys et al. (2019) established excellent reliability for the PPQ $(\rho>0.90)$.

The Turnover Intention Scale (TIS; Sjöberg \& Sverke, 2000) measured turnover intention. Scored on a five-point scale ( 1 = strongly disagree, $5=$ strongly agree $)$, the TIS encompasses three items on a solitary dimension. A sample item is: 'I am actively looking for other jobs'. In a South African study, Rossouw and Rothmann (2020) established a Cronbach's alpha coefficient of 0.84 for the TIS.

The In-Role Behaviour Scale (Williams \& Anderson, 1991) measured in-role performance. Scored on a seven-point scale ( 1 = strongly disagree, 7 = strongly agree), the scale encompasses seven items on a solitary dimension. A sample item is: 'I fulfil responsibilities specified in my job description'. The items were formulated in a way that allowed participants to evaluate their own performance as the Department of Education prohibited external evaluation. In a South African study, Dhliwayo and Coetzee (2020) established a Cronbach's alpha coefficient of 0.83 for the scale.

The Organisational Citizenship Behaviour Scale (OCBS; Rothmann, 2010) measured both OCB (others) and OCB (organisation). Scored on a seven-point scale $(1=$ strongly disagree, $7=$ strongly agree), each dimension encompasses three items. A sample item for OCB others is: 'I assist others with their duties'. 'I offer ideas to improve the functioning of the organisation' is a sample item of OCB organisation. In a South African study, Sepeng, Stander, Van der Vaart and Coxen (2020) established acceptable reliability coefficients for the OCBS $(\omega=0.79, \alpha=0.79)$. 


\section{Procedure}

To conduct research amongst secondary school teaching staff, the researcher had to complete a research request form obtained from the Gauteng Department of Education (GDE). The completed form was sent to the GDE's research division for approval. Once the GDE approved the study, scientific and ethics clearance could be obtained and further arrangements could be made with the selected district offices (Sedibeng East and West), principals, and probable participants. Teaching personnel at the participating schools received a clear outline of the study and an informed consent form and were made aware that they were by no means obliged to participate in the study. The teaching personnel included anyone (teacher, head of department, vice-principal or principal) fulfilling some sort of teaching role in either a permanent or school governing body position. Paper-based surveys were circulated amongst consenting participants. Arrangements were made for the secure return of participants' survey papers.

\section{Statistical analysis}

Two statistical software programmes were used to analyse the dataset: Mplus version 8.4 (Muthén \& Muthén, 1998-2017) and JASP version 0.14 (JASP Team, 2020). Descriptive statistics (means and standard deviations), Cronbach's alpha coefficients $(\alpha)$ and McDonald's omega coefficients $(\omega)$ were calculated by using JASP. Composite reliability coefficients $(\rho)$ were calculated by using Mplus. Reliability coefficients reflect measurement consistency (Netemeyer, Bearden, \& Sharma, 2003) and play a crucial part in assessing the psychometric properties of a measuring instrument. For the preceding reliability coefficients, values $\geq 0.70$ were deemed to be acceptable according to Nunnally and Bernstein's (1994) guidelines. John and Soto (2007), however, suggested that:

[A]lthough it would be quite convenient to have a simple cookbook for measurement decisions, there is no minimum or optimum reliability that is necessary, adequate, or even desirable in all contexts. (p. 464)

Consequently, the $\geq 0.70$ benchmark is not set in stone and should be cautiously interpreted with a specific context in mind (John \& Soto, 2007; Pedhazur \& Schmelkin, 1991). Correlations, confirmatory factor analysis and structural equation modelling were also tested by using Mplus. Values $\leq 0.05$ indicated statistical significance ( $p$-values), whilst the practical significance of the correlation coefficients according to Cohen's (1992) criteria were as follows: 0.10 to 0.29 (small effect), 0.30 to 0.49 (medium effect) and $\geq 0.50$ (large effect). To assess the fit of the measurement models (using confirmatory analysis) and the structural model (using structural equation modelling), the standard Mplus fit indices were used. Values $\geq 0.90$ are deemed to be acceptable for the Tucker-Lewis index (TLI) and the comparative fit index (CFI) (Wang \& Wang, 2020). Values $\leq 0.08$ are acceptable for the root mean square error of approximation (RMSEA) (Browne \& Cudeck, 1993) and the standardised root mean square residual (SRMR) (Hu \& Bentler, 1999).
Although there are no cut-off values for the Chi-square statistic $\left(\chi^{2}\right)$, or the Akaike and Bayes information criteria (BIC), lower values usually indicate a better model fit. When a model displays acceptable fit according to the preceding criteria, it means that valid deductions can be made regarding aspects, such as the proposed relationships in the study and the factor structure/s of the respective constructs, amongst other things. Regarding the variance explained $\left(R^{2}\right)$ in the structural model, values $\leq 0.09$ indicated a small effect, values $<0.25$ indicated a medium effect and values $\geq 0.25$ indicated a large effect (Cohen, 1988).

\section{Ethical considerations}

Ethical clearance for the study was granted by the HHREC Committee, North-West University (No.:NWU-HS-2015-0193).

\section{Results}

Descriptive statistics, reliability coefficients and correlations are reported in Table 1.

As shown in Table 1, the correlation coefficients between almost all of the latent variables were statistically significant $(p \leq 0.001)$. The correlation between turnover intention and in-role performance $(p=0.03)$, as well as between turnover intention and OCB others $(p=0.003)$, was also statistically significant, although it displayed higher $p$-values in comparison with the rest. In terms of the practical significance of the correlation coefficients, small, medium and large effects were observed. All of the measuring instruments exceeded the reliability threshold of 0.70 on all the reliability indicators used in the study, ranging from 0.80 to 0.98 . Accordingly, the measuring instruments exhibited sufficient measurement consistency.

\section{Confirmatory factor analysis}

To assess the validity of the measuring instruments, confirmatory factor analyses were carried out using Mplus. Confirmatory factor analysis is generally used to test existing theoretical frameworks (Matsunaga, 2010) and provides information regarding the factor structure of a construct (e.g. whether it is unidimensional or multidimensional), how well items load onto their intended construct (e.g. factor loadings) and so on. Two measurement models were specified and tested for fit purposes using the maximum likelihood robust (MLR) estimator. The MLR estimator was used as it takes skewness and kurtosis into account (Kline, 2016).

In the original hypothesised model, positive practices were specified as a second-order factor, entailing respect (seven observed variables $\left.{ }^{6}\right)$, support (seven observed variables), caring (four observed variables), meaning (five observed variables), inspiration (three observed variables) and forgiveness (three observed variables). The remaining

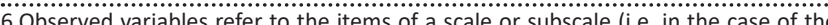
respect subscale, seven items were used in specifying the construct based on theory). The same principle applies to the rest of the scales and subscales. The number of observed variables should correspond to the number of items of each scale and subscale as outlined in the 'measuring instruments' section of this study. 
variables were all specified as first-order factors: turnover intention (three observed variables), in-role performance (seven observed variables), OCB others (three observed variables) and OCB organisation (three observed variables). The fit statistics for the model were as follows: $\chi^{2}=1943.45$, $d f=929, \chi^{2} / d f=2.09, \mathrm{CFI}=0.90, \mathrm{TLI}=0.89, \mathrm{RMSEA}=0.06$ $(90 \%$ confidence intervals $[\mathrm{CIs}]=0.06,0.007)$, and SRMR $=$ 0.06 . Because of the TLI's slight underperformance $(<0.90)$, the researcher looked at high modification indices to see whether the model fit can be improved. A modification index value of 88.08 was established between item 6 ('I neglect aspects of the job that I am obligated to perform') and item 7 ('I fail to perform essential duties') of the In-Role Behaviour Scale (Williams \& Anderson, 1991). As these items formed part of the same construct (in-role performance) and both were reverse scored, they were allowed to correlate. Following the adjustments, the model yielded the following acceptable fit results: $\chi^{2}=1835.648, d f=928, \chi^{2} / d f=1.98$, $\mathrm{CFI}=0.91, \mathrm{TLI}=0.90, \mathrm{RMSEA}=0.06(90 \% \mathrm{CI}=0.06,0.07)$ and $\mathrm{SRMR}=0.05$. In an alternative measurement model, positive practices were specified as a first-order factor, entailing 29 observed variables. The fit statistics for the model were as follows: $\chi^{2}=2791.262, d f=934, \chi^{2} / d f=2.99, \mathrm{CFI}=0.82, \mathrm{TLI}=$ 0.81 , RMSEA $=0.09(90 \% \mathrm{CI}=0.08,0.09)$ and SRMR $=0.06$. From the preceding results, the original hypothesised model comfortably displayed the best fit. The acceptable fit statistics from the original hypothesised model suggests that the data adequately captured the constructs of the study, and that further relationships between the variables can be assessed. Consequently, using the specifications of the first model, the researcher proceeded to add structural paths to the equation (i.e. regress the dependent variables of the study onto the independent variable).

\section{Structural equation modelling}

Figure 1 illustrates the standard path coefficients from the independent variable (positive practices) to the dependent variables (turnover intention, in-role performance, OCB others and OCB organisation).

The structural path from positive practices to turnover intention was statistically significant, and the direction of the relationship was negative as anticipated $(\beta=-0.53 ; p=<0.001)$. Positive practices explained 29\% (large effect) of the variance in turnover intention. Consequently, Hypothesis 1 is supported.

The structural path from positive practices to in-role performance was statistically significant, and the direction of the relationship was positive as anticipated ( $\beta=0.22 ; p=<0.001$ ). Positive practices explained 5\% (small effect) of the variance in in-role performance. Consequently, Hypothesis 2 is partially supported.

The structural path from positive practices to OCB others was statistically significant, and the direction of the relationship was positive as anticipated $(\beta=0.45 ; p=<0.001)$. Positive practices explained $21 \%$ (medium effect) of the variance in OCB others. Consequently, Hypothesis 3 is supported.

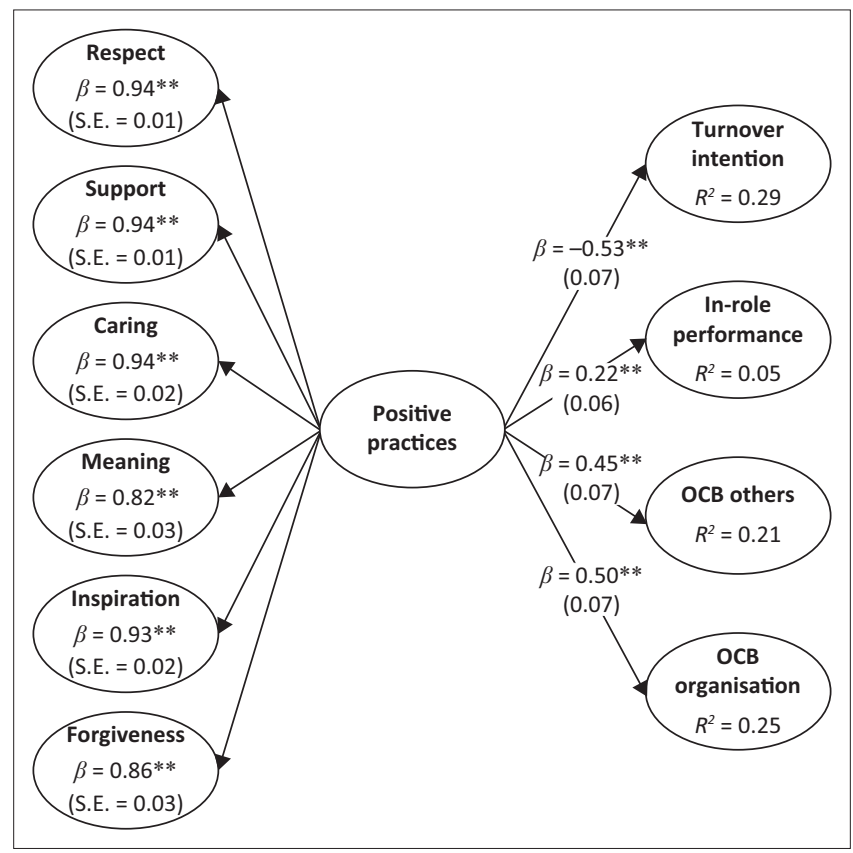

S.E., standard error; $O C B$, organisational citizenship behaviours.

FIGURE 1: Structural model of positive practices, turnover intention, in-role performance and organisational citizenship behaviours (towards others and the organisation).

TABLE 1: Descriptive statistics, reliability coefficients and correlations.

\begin{tabular}{|c|c|c|c|c|c|c|c|c|c|c|c|c|c|c|c|}
\hline Variable & $M$ & SD & $\rho$ & $\omega$ & $\alpha$ & 1 & 2 & 3 & 4 & 5 & 6 & 7 & 8 & 9 & 10 \\
\hline 1. Respect & 3.54 & 0.92 & 0.96 & 0.96 & 0.96 & - & - & - & - & - & - & - & - & - & - \\
\hline 2. Support & 3.69 & 0.96 & 0.96 & 0.96 & 0.96 & $0.88 * *$ & - & - & - & - & - & - & - & - & - \\
\hline 3. Caring & 3.46 & 0.97 & 0.95 & 0.95 & 0.94 & $0.87 * *$ & $0.88 * *$ & - & - & - & - & - & - & - & - \\
\hline 4. Meaning & 3.45 & 0.91 & 0.94 & 0.94 & 0.94 & $0.77 * *$ & $0.78 * *$ & $0.77 * *$ & - & - & - & - & - & - & - \\
\hline 5. Inspiration & 3.46 & 1.01 & 0.93 & 0.93 & 0.93 & $0.87 * *$ & $0.88 * *$ & $0.87 * *$ & $0.77 * *$ & - & - & - & - & - & - \\
\hline 6. Forgiveness & 3.09 & 1.03 & 0.90 & 0.90 & 0.90 & $0.81 * *$ & $0.81 * *$ & $0.81 * *$ & $0.71 * *$ & $0.81 * *$ & - & - & - & - & - \\
\hline 8. Turnover intention & 2.81 & 1.29 & 0.91 & 0.91 & 0.90 & $-0.50 * *$ & $-0.50 * *$ & $-0.50 * *$ & $-0.44 * *$ & $-0.50 * *$ & $-0.46 * *$ & $-0.53 * *$ & - & - & - \\
\hline 9. In-role performance & 6.21 & 0.73 & 0.80 & 0.80 & 0.83 & $0.20 * *$ & $0.21 * *$ & $0.20 * *$ & $0.18 * *$ & $0.20 * *$ & $0.19 * *$ & $0.22 * *$ & $-0.15^{*}$ & - & - \\
\hline 10. OCB others & 5.29 & 1.14 & 0.80 & 0.81 & 0.80 & $0.42 * *$ & $0.43 * *$ & $0.42 * *$ & $0.37 * *$ & $0.42 * *$ & $0.39 * *$ & $0.45 * *$ & $-0.22 * *$ & $0.39 * *$ & - \\
\hline 11. OCB organisation & 5.42 & 1.16 & 0.84 & 0.84 & 0.84 & $0.47 * *$ & $0.48 * *$ & $0.47 * *$ & $0.41 * *$ & $0.47 * *$ & $0.43 * *$ & $0.51^{* *}$ & $-0.34 * *$ & $0.36 * *$ & $0.61 * *$ \\
\hline
\end{tabular}

$\mathrm{M}$, mean; SD, standard deviation; $\rho$, composite reliability; $\omega$, McDonald's omega coefficient; $\alpha$, Cronbach's alpha coefficient; OCB, organisational citizenship behaviour.

All correlations are statistically significant, $p<0.01^{* *} ; p<0.05^{*}$.

Practical significance: 0.10 to 0.29 (small effect), 0.30 to 0.49 (medium effect) and $\geq 0.50$ (large effect) as per Cohen's (1992) guidelines. 
The structural path from positive practices to OCB organisation was statistically significant, and the direction of the relationship was positive as anticipated $(\beta=0.50$; $p=<0.001$ ). Positive practices explained 25\% (large effect) of the variance in OCB organisation. Consequently, Hypothesis 4 is supported.

\section{Discussion}

This study set out to inspect associations amongst positive practices, turnover intention, in-role performance and OCBs towards others and the organisation.

The results confirmed the negative association between positive practices and turnover intention, whilst positive associations were established amongst positive practices, inrole performance (to a lesser extent) and the two different types of OCBs used in this study. Consequently, employees are less likely to contemplate departure from their current organisation, are more prone to satisfactorily execute their formal work tasks and are more inclined to walk the extra mile for their colleagues and organisation when positive practices are embedded in the school environment. The positive association between positive practices and in-role performance is partially in line with the findings of Cameron et al. (2011), although different levels of analysis came into effect. To the best of the researcher's knowledge, this was the first study to assess relationships between positive practices, turnover intention and OCBs. In this regard, the study makes a valuable contribution to POS. In general, the findings seem to support the reciprocity principle of SET whereby positive treatment from one entity is matched with positive treatment from another entity (Cropanzano \& Mitchell, 2005).

\section{Implications for management}

When looking at the findings of this study, a classic case of 'you reap what you sow' springs to mind. Although not all employees will value reciprocity to the same extent (Cropanzano \& Mitchell, 2005), some researchers (e.g. Gouldner, 1960; Wang, Tsui, Zhang, \& Ma, 2003) believe in its universality. Therefore, when an employee perceives unfavourable treatment from either his or her colleagues or organisation, he or she will be more inclined to act negatively towards the entity from which the negative treatment originates. For example, when the negative treatment is received from colleagues, an employee is unlikely to offer any form of assistance to that specific colleague or a group of colleagues. Similarly, when the negative treatment stems from the organisation, an employee may retaliate through withdrawal behaviours, as well as a decrease in performance (in-role and extra-role). In contrast, when employees are treated well, a vast range of positive outcomes may ensue. Therefore, organisations are faced with two options: create a respectful, supportive, caring, inspirational, meaningful and forgiving organisational environment for employees and see them prosper and take the organisation to greater heights, or treat them poorly and bear the consequences.
This poses the question: how does one cultivate positive practices in one's organisation? Unfortunately, there is no straightforward answer as this will vary from organisation to organisation. Therefore, it is important for organisations to obtain direct input from their employees regarding how they perceive organisational practices (e.g. negative, neutral and positive). Information can be obtained through sources, such as focus groups, surveys or interviews. Obtaining information from as many employees as possible is important because of differences in individual perceptions. Richer data may assist organisations to identify the areas that warrant the most attention. Accordingly, organisations can use this information to implement strategies aimed at rectifying negative or neutral areas, as well as strategies to reinforce current practices that are positively perceived. When organisations extensively and continuously invest in creating a better work atmosphere for their employees, a host of positive outcomes should follow.

\section{Limitations and recommendations for future research}

The study was not free from limitations. Firstly, positive practices were not assessed at the organisational level of analysis as the researcher could not obtain enough participants from each school to aggregate their responses. It would be interesting to see if the individual-level results in the current study correspond to analyses conducted at the team, business-unit or organisational level. This could be a topic of interest for future studies. Secondly, by using a cross-sectional design, the author cannot definitively imply that positive practices will cause any of the outcomes tested in the study. Future studies using longitudinal designs may shed more light on this topic. Finally, some researchers may argue that self-reported measures (as used in the current study) may lead to common method bias (Podsakoff, MacKenzie, Lee, \& Podsakoff, 2003). Although not always feasible (like certain measures utilised in this study), collecting information from other sources in addition to self-reported measures may provide valuable insights.

\section{Conclusion}

The embodiment of respectful, supportive, caring, inspirational, meaningful and forgiving organisational practices should positively impact employee retention, performance and helping behaviours.

\section{Acknowledgements Competing interests}

The author declares that he has no financial or personal relationships that may have inappropriately influenced him in writing this article.

\section{Author's contributions}

K.R. declares that he is the sole author of this research article. 


\section{Funding information}

The author received no financial support for the research, authorship and/or publication of this article.

\section{Data availability}

Only the primary researcher has access to the primary data as approved by the ethics committee.

\section{Disclaimer}

The views expressed in this article are those of the author and do not reflect the official position or policy of any affiliated agency or institution of the author.

\section{References}

Borman, W.C., \& Motowidlo, S.J. (1997). Task performance and contextual performance: The meaning for personnel selection research. Human Performance, 10(2), 99-109. https://doi.org/10.1207/s15327043hup1002_3

Browne, M.W., \& Cudeck, R. (1993). Alternative ways of assessing model fit. In K.A. Bollen \& J.S. Long (Eds.), Testing structural equation models (pp. 136-162). Newbury Park: Sage.

Cameron, K., Mora, C., Leutscher, T., \& Calarco, M. (2011). Effects of positive practices on organizational effectiveness. The Journal of Applied Behavioral Science, 47(3) 266-308. https://doi.org/10.1177/0021886310395514

Cameron, K.S., \& Spreitzer, G.M. (Eds.). (2011). The Oxford handbook of positive organizational scholarship. New York: Oxford University Press.

Cohen, J. (1988). Statistical power analysis for the behavioral sciences. New York: Academic Press.

Cohen, J. (1992). A power primer. Psychological Bulletin, 12(1), 155-159. https://doi. org/10.1037/0033-2909.112.1.155

Collie, R.J., Shapka, J.D., \& Perry, N.E. (2012). School climate and social-emotional learning: Predicting teacher stress, job satisfaction, and teaching efficacy. Journal of Educational Psychology, 104(4), 1189-1204. https://doi.org/10.1037/ a0029356

Cropanzano, R., \& Mitchell, M.S. (2005). Social exchange theory: An interdisciplinary review. Journal of Management, 31(6), 874-900. https://doi. org/10.1177/0149206305279602

Dhliwayo, P., \& Coetzee, M. (2020). Cognitive intelligence, emotional intelligence and personality types as predictors of job performance: Exploring a model for personality types as predictors of job performance: Exploring a model for
personnel selection. SA Journal of Human Resource Management, 18, a1348. https://doi.org/10.4102/sajhrm.v18i0.1348

DiPaola, M.F., \& Tschannen-Moran, M. (2001). Organizational citizenship behavior in schools and its relationship to school climate. Journal of School Leadership, 11(5) 424-447. https://doi.org/10.1177/105268460101100503

Fouché, E. (2015). Well-being of teachers in secondary schools. Doctora dissertation, North-West University. Retrieved from https://hdl.handle. net/10394/17015

García-Carmona, M., Marín, M.D., \& Aguayo, R. (2019). Burnout syndrome in secondary school teachers: A systematic review and meta-analysis. Socia Psychology of Education, 22(1), 189-208. https://doi.org/10.1007/s11218-0189471-9

Geue, P.E. (2018). Positive practices in the workplace: Impact on team climate, work engagement, and task performance. The Journal of Applied Behavioral Science, 54(3), 272-301. https://doi.org/10.1177/0021886318773459

Gouldner, A.W. (1960). The norm of reciprocity: A preliminary statement. American Sociological Review, 25(2), 161-178. https://doi.org/10.2307/2092623

Hu, L., \& Bentler, P.M. (1999). Cut-off criteria for fit indexes in covariance structural analysis: Conventional criteria versus new alternative. Structural Equation modelling: A Multidisciplinary Journal, 6(1), 1-55. https://doi. org/10.1080/10705519909540118

Imran, R., Allil, K., \& Mahmoud, A.B. (2017). Teacher's turnover intentions: Examining the impact of motivation and organizational commitment. International Journal of Educational Management, 31(6), 828-842. https://doi.org/10.1108/IJEM-052016-0131

Janse van Rensburg, C., \& Rothmann, S. (2020). Towards positive institutions: Positive practices and employees' experiences in higher education institutions. SA Journa of Industrial Psychology, 46(1), 1-11. https://doi.org/10.4102/sajip.v46i0.1733

JASP Team. (2020). JASP (Version 0.14.1)[Computer software]. Retrieved from https:// jasp-stats.org/

John, O.P., \& Soto, C.J. (2007). The importance of being valid: Reliability and the process of construct validation. In R.W. Robins, R.C. Fraley, \& R.F. Krueger (Eds.), Handbook of research methods in personality psychology (pp. 461-494). New York: The Guilford Press.
Kline, R.B. (2016). Principles and practice of structural equation modeling (4th edn.). New York: Guilford Press.

Lambert, S.J. (2006). Both art and science: Employing organizational documentation in workplace-based research. In M. Pitt-Catsouphes, E.E. Kossek, \& S. Sweet (Eds.) The work and family handbook: Multi-disciplinary perspectives, methods, and approaches (pp. 503-525). Mahwah: Lawrence Erlbaum Associates.

Martínez-Monteagudo, M.C., Inglés, C.J., Granados, L., Aparisi, D., \& García-Fernández, J.M. (2019). Trait emotional intelligence profiles, burnout, anxiety, depression, and stress in secondary education teachers. Personality and Individual Differences, 142, 53-61. https://doi.org/10.1016/j.paid.2019.01.036

Matsunaga, M. (2010). How to factor-analyze your data right: Do's, don'ts, and how to's. International Journal of Psychological Research, 3(1), 97-110. https://doi. org/10.21500/20112084.854

Mitchell, M.S., Cropanzano, R.S., \& Quisenberry, D.M. (2012). Social exchange theory, exchange resources, and interpersonal relationships: A modest resolution of theoretical difficulties. In K. Törnblom \& A. Kazemi (Eds.), Handbook of socia resource theory (pp. 99-118). New York: Springer.

Muthén, L.K., \& Muthén, B.O. (1998-2017). Mplus user's guide (8th edn.). Los Angeles: Muthén \& Muthén.

Netemeyer, R.G., Bearden, W.O., \& Sharma, S. (2003). Scale development in the socia sciences: Issues and applications. Thousand Oaks: Sage.

Ng, Y.M., Voo, P., \& Maakip, I. (2019). Psychosocial factors, depression, and musculoskeletal disorders among teachers. BMC Public Health, 19(1), 234. https://doi.org/10.1186/s12889-019-6553-3

Nunnally, J.C., \& Bernstein, I.H. (1994). Psychometric theory (3rd edn.). New York: McGraw-Hill.

Pedhazur, E.J., \& Schmelkin, L.P. (1991). Measurement, design, and analysis: An integrated approach. Hillsdale: Lawrence Erlbaum Associates.

Perryman, J., \& Calvert, G. (2020). What motivates people to teach, and why do they leave? Accountability, performativity and teacher retention. British Journal of Educational Studies, 68(1), 3-23. https://doi.org/10.1080/00071005.2019.158 9417

Podsakoff, P.M., MacKenzie, S.B., Lee, J.Y., \& Podsakoff, N.P. (2003). Common method biases in behavioral research: A critical review of the literature and recommended remedies. Journal of Applied Psychology, 88(5), 879-903. https://doi. remedies. Journal of Applied
org/10.1037/0021-9010.88.5.879

Rautenbach, C. (2015). Flourishing of employees in a fast moving consumable goods environment. Doctoral dissertation, North-West University. Retrieved from https://hdl.handle.net/10394/17030

Redelinghuys, K., Rothmann, S., \& Botha, E. (2019). Flourishing-at-work: The role of positive organizational practices. Psychological Reports, 122(2), 609-631. https:// doi.org/10.1177/0033294118757935

Rossouw, E.A., \& Rothmann, S. (2020). Work beliefs, work-role fit, and well-being of judges in South Africa: Effects on intention to leave and organisational citizenship behaviour. Journal of Psychology in Africa, 30(4), 277-288. https://doi.org/10.108 0/14330237.2020.1777032

Rothmann, S. (2010). The reliability and validity of measuring instruments of happiness in the Southern African context. Unpublished research report, NorthWest University.

Ryan, S.V., Nathaniel, P., Pendergast, L.L., Saeki, E., Segool, N., \& Schwing, S. (2017) Leaving the teaching profession: The role of teacher stress and educationa accountability policies on turnover intent. Teaching and Teacher Education, 66, 1-11. https://doi.org/10.1016/j.tate.2017.03.016

Saloviita, T., \& Pakarinen, E. (2021). Teacher burnout explained: Teacher-, studentand organisation-level variables. Teaching and Teacher Education, 97, 103221 https://doi.org/10.1016/j.tate.2020.103221

Sepeng, W., Stander, M.W., Van der Vaart, L., \& Coxen, L. (2020). Authentic leadership organisational citizenship behaviour and intention to leave: The role of psychological capital. SA Journal of Industrial Psychology, 46(1), a1802. https:// doi.org/10.4102/sajip.v46i0.1802

Sjöberg, A., \& Sverke, M. (2000). The interactive effect of job involvement and organizational commitment on job turnover revisited: A note on the mediating role of turnover intention. Scandinavian Journal of Psychology, 41(3), 247-252. https://doi.org/10.1111/1467-9450.00194

Skaalvik, E.M., \& Skaalvik, S. (2018). Job demands and job resources as predictors of teacher motivation and well-being. Social Psychology of Education, 21(5), 1251-1275. https://doi.org/10.1007/s11218-018-9464-8

Tett, R.P., \& Meyer, J.P. (1993). Job satisfaction, organizational commitment, turnover intention, and turnover: Path analyses based on meta-analytic findings. Personnel
Psychology, 46(2), 259-293. https://doi.org/10.1111/j.1744-6570.1993. Psychology,
tb00874.x

Wang, D., Tsui, A.S., Zhang, Y., \& Ma, L. (2003). Employment relationships and firm performance: Evidence from an emerging economy. Journal of Organizational Behavior, 24(5), 511-534. https://doi.org/10.1002/job.213

Wang, J., \& Wang, X. (2020). Structural equation modelling (2nd edn.). Hoboken: Wiley \& Sons Inc.

Williams, L.J., \& Anderson, S.E. (1991). Job satisfaction and organizational commitment as predictors of organizational citizenship and in-role behaviors. Journal of Management, 17(3), 601-617. https://doi.org/10.1177/014920639101700305

Yang, C., Jenkins, L., Fredrick, S.S., Chen, C., Xie, J.S., \& Nickerson, A.B. (2019). Teacher victimization by students in China: A multilevel analysis. Aggressive Behavior 45(2), 169-180. https://doi.org/10.1002/ab.21806 